\title{
Simultaneous removal of multiple odorants from source water suffering from septic and musty odors: Verification in a full-scale water treatment plant with ozonation
}

\author{
Qingyuan Guo a, Kai Yang a , Jianwei Yu ${ }^{\text {a, * }}$, Chunmiao Wang ${ }^{a}$, Xiaodong Wen ${ }^{\text {a, c }}$, \\ Liping Zhang ${ }^{c}$, Min Yang ${ }^{b}$, Ping Xia ${ }^{\mathrm{d}}$, Dong Zhang ${ }^{\mathrm{d}}$ \\ ${ }^{a}$ Key Laboratory of Drinking Water Science and Technology, Research Center for Eco-Environmental Sciences, Chinese Academy of Sciences, Beijing, 100085, \\ China \\ b State Key Laboratory of Environmental Aquatic Chemistry, Research Center for Eco-Environmental Sciences, Chinese Academy of Sciences, Beijing, 100085, \\ China \\ ${ }^{c}$ School of Chemical and Environmental Engineering, China University of Mining and Technology, Beijing, 100085, China \\ ${ }^{\mathrm{d}}$ Shanghai National Engineering Research Center of Urban Water Resources Co., Ltd., Shanghai, 200082, China
}

\section{A R T I C L E I N F O}

Article history:

Received 5 March 2016

Received in revised form 1 May 2016

Accepted 4 May 2016

Available online 4 May 2016

\section{Keywords:}

Odor (odorant) removal

Ozonation

Biological activated carbon (BAC)

Odor activity value (OAV)

\begin{abstract}
A B S T R A C T
Ozonation is known to be very effective in the removal of odorants from source water. However, it is not known if ozonation is effective in the removal of multiple odorants causing different types of odors. In this study, the removal performance for odors and odorants were evaluated in a Water Treatment Plant (WTP), which was equipped with coagulation, sedimentation, ozonation, biological activated carbon (BAC) filtration, sand filtration, and chlorination in succession and located in the downstream of the Huangpu (HP) River, over the period from April, 2014 to April, 2015. Flavor profile analysis (FPA) results showed that the source water was constantly associated with septic and musty odors. Geosmin and 2MIB, with an average OAV of 4.54 and 1.38 , respectively, were the major odorants for musty odor, while bis(2-chloroisopropyl) ether, DEDS and DMDS with an average OAV of 2.35, 1.65 and 0.78, respectively, might be responsible for the septic odor. While the musty odor could be removed effectively through the combination of ozonation and BAC, the septic odor and associated odorants required further treatment with sand filtration and chlorination for complete removal. It is clear that the advanced treatment process was effective for the treatment of source water containing complicated odorants. It should be noted that the sedimentation process needs careful management because release of odorants may occur during the treatment. The result of this study will be helpful for the mitigation of odors in WTP using source waters suffering from complicated odor problems.
\end{abstract}

๑) 2016 Elsevier Ltd. All rights reserved.

\section{Introduction}

Unpleasant odor in drinking water is unacceptable for consumers, and thus has always been a big issue for water supply companies (Suffet et al., 1999; Yang et al., 2008). Occurrences of seasonal musty/earthy odors caused by some typical algal metabolites, including 2-methylisoborneol (2-MIB) and geosmin, have often been reported worldwide (Lin et al., 2002; Sun et al., 2013). Though reported less frequently, the septic odor caused by compounds such as thioethers and thiols is another important odor

\footnotetext{
* Corresponding author.

E-mail address: jwyu@rcees.ac.cn (J. Yu).
}

type because of its strong impact on human perception (Schiffman et al., 2001; Yang et al., 2008; Yu et al., 2009). These two types of odors have been those most frequently encountered in the source waters of China, according to a nationwide survey (Sun et al., 2014).

The conventional water treatment process including coagulation, sedimentation, filtration and chlorination has proved to be almost completely ineffective in the removal of the major reported odorants such as 2-MIB and geosmin (Persson et al., 2007; Jo et al., 2011; Srinivasan and Sorial, 2011). Ozone oxidation and biodegradation by biological activated carbon have been considered to be two effective methods for mitigation of the odor problem (Newcombe et al., 1997; Geering, 1999; Cook et al., 2001; von Gunten, 2003a) The combination of ozonation and biological 
activated carbon (BAC) $\left(\mathrm{O}_{3}-\mathrm{BAC}\right)$, which integrates the oxidation effect of $\mathrm{O}_{3}$ and the biological degradation effect of BAC, have often been adopted as an advanced water treatment approach because of its capability in comprehensively improving drinking water quality (Newcombe and Cook, 2002). Though the $\mathrm{O}_{3}$-BAC process has been proved to be effective in the removal of odors (Cook et al., 2001; Newcombe and Cook, 2002), most of the previous studies have mainly been limited to the earthy odorants including 2-MIB and geosmin (Srinivasan and Sorial, 2011; Antonopoulou et al., 2014). Ozonation and associated advanced oxidation processes $\left(\mathrm{O}_{3} / \mathrm{H}_{2} \mathrm{O}_{2}\right.$, $\mathrm{UV} / \mathrm{O}_{3}, \mathrm{UV} / \mathrm{O}_{3} / \mathrm{H}_{2} \mathrm{O}_{2}$ ) have been proved to be effective for the removal of 2-MIB and geosmin (Atasiet et al., 1999; Ho et al., 2002; Jung et al., 2004; Liang et al., 2007; Andreadakis et al., 2010; Mizuno et al., 2011). It is possible that different types of odorants may coexist in some source waters. For example, twenty odorants of eight categories with 2-3 orders of magnitude difference in odor threshold concentrations (OTCs) have been detected with a wide range of differences in concentration levels in Huangpu (HP) River source water in a water quality survey (Guo et al., 2015). Therefore, most odor events in drinking waters have been caused by multiple odorants (Khiari et al., 1995; Suffet et al., 1999). However, studies to explore the effectiveness of the $\mathrm{O}_{3}-\mathrm{BAC}$ process in the mitigation of odors in source waters containing widely varying OTCs and concentration levels are still very limited (Srinivasan and Sorial, 2011; Antonopoulou et al., 2014).

The Huangpu (HP) River, an important source water for Shanghai, has long been suffering from complicated odor problems, particularly the septic and musty odors (Sun et al., 2013; Guo et al., 2016). In order to completely abate the odor problem, the $\mathrm{O}_{3}-\mathrm{BAC}$ process has recently been adopted for all of the Water Treatment Plants (WTPs) using HP River source water. In this study, a WTP adopting a water treatment process mainly including coagulation, sedimentation, ozonation, BAC filtration, sand filtration and chlorination in succession was evaluated for its performance in the mitigation of the septic and musty odors as well as the removal of the major odorants over a period of 13 months. Flavor profile analysis (FPA) (APHA, 2005) was used to evaluate the odor characteristics of water samples taken from the inlet and outlet of each treatment unit, and comprehensive two-dimensional gas chromatography with time-of-flight mass spectrometry (GC $\times$ GC-TOFMS) was used to quantify the odorants. The result of this study will be helpful for the mitigation of odors in WTP using source waters suffering from complicated odor problems.

\section{Materials and methods}

\subsection{Information on studied WTP and sampling procedure}

As shown in Fig. S1, the studied WTP, which takes source water directly from the HP River and has a maximum capacity of $200,000 \mathrm{~m}^{3} / \mathrm{d}$, mainly consists of coagulation, sedimentation, ozonation, BAC filtration and sand filtration in succession. Aluminum sulfate was adopted as coagulant ( $40 \mathrm{mg} / \mathrm{L}$ ), the settling time and flow velocity of the horizontal flow sedimentation tank were $105 \mathrm{~min}$ and $49.6 \mathrm{~m} / \mathrm{h}$, and the settled sludge was removed once a day. The ozone dose was $1.0 \mathrm{mg} / \mathrm{L}$ with reaction time of $15 \mathrm{~min}$. The empty bed contact time and filtration velocity of the activated carbon filter were $16 \mathrm{~min}$ and $8.3 \mathrm{~m} / \mathrm{h}$, respectively. Sodium hypochlorite was added after sand filtration for disinfection (15 mg/L).

Over the period from April, 2014 to April, 2015, samples were taken from the raw water pipe and the effluents from the sedimentation, ozonation, BAC, and clean water basin units once a month. In order to take samples in the same "batch" of water, the specific retention time in each treatment unit was considered during the sampling.

All sampling taps were fully rinsed prior to taking samples and $1 \mathrm{~L}$ water was obtained in an amber glass bottle with no head space at each sampling point. These water samples were transported to the laboratory immediately in an insulated box with added ice bags to maintain the temperature below $4{ }^{\circ} \mathrm{C}$. Sensory characteristics of the water samples were evaluated using FPA (APHA, 2005) immediately once received, and pre-concentration using liquid-liquid extraction (LLE) for odorant determination through GC $\times$ GCTOFMS analysis was completed within two days (Guo et al., 2015). Every batch of water sample was analyzed in duplicate, and the odorants' concentrations were the average values of the parallel analyses.

\subsection{Chemicals and reagents}

Fifty-four odorant standards of eleven groups, namely, aldehydes, benzenes, ethers, esters, indoles, ketones, pyrazines, pyridines, phenols, thioethers, thiols, etc., (Guo et al., 2015) were purchased at the highest level of purity from Sigma-Aldrich (USA). Stock solutions of $1000 \mathrm{mg} / \mathrm{L}$ for standards were prepared by diluting different standard solutions with HPLC grade methanol. Solvents including acetone, methanol and methylene chloride of HPLC grade were purchased from Fisher Scientific Co. (China). Reagents including $\mathrm{NaCl}$ and anhydrous $\mathrm{Na}_{2} \mathrm{SO}_{4}$ were purchased at guaranteed reagent purity grade from Beijing Chemicals Ltd. (China), which were heated to $450^{\circ} \mathrm{C}$ for $2 \mathrm{~h}$ before use. Ultrapure deionized water $(18 \mathrm{M} \Omega \mathrm{cm}$ ) was produced with a Milli-Q purification system.

\subsection{Sensory analysis}

FPA was used to evaluate the odor characteristics of water samples; a detailed description of the training and application procedures can be found in the Standard Methods for Water and Wastewater (APHA, 2005). Namely, 3-4 non-smokers between 24 and 45 years of age with normal olfactory function and no known anosmia were selected as the panelists. Seven-point scales of 1-12 were used to describe the intensity of samples (1: odor threshold, 2\&4: soft odor intensity, 6\&8: moderate odor intensity, 10\&12: strong odor intensity).

\subsection{Odorant quantification}

The concentrations of the 54 odorants in water sample extracts were determined using a GC $\times$ GC-TOFMS system (Pegasus-4D, LECO, USA) equipped with a multipurpose sampler (Gerstel, Germany). GC $\times$ GC was linked by a two-stage modulator. The first dimension (the column in the main GC oven) was configured as a commonly used a low polarity column, while the second dimension adopted a polar column for better separation of extracts. The specific operating conditions can be found in our previous study (Guo et al., 2015).

Odor activity value (OAV), which was calculated by dividing the odorant concentration by the corresponding OTC, was employed to evaluate the contribution of different odorants to the odor profile (Burdack-Freitag and Schieberle, 2012). The odor characteristics and OTC values of the odorants are listed in Table S1 (Guo et al., 2015).

\section{Results and discussion}

\subsection{Mitigation of the septic and musty odors}

As shown in Fig. 1, the HP source water was mainly associated 


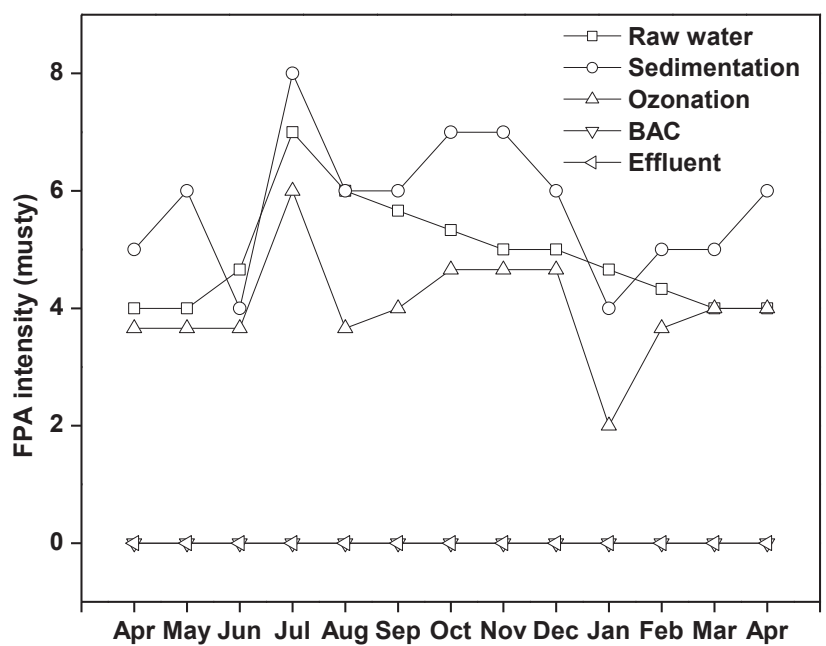

(a)

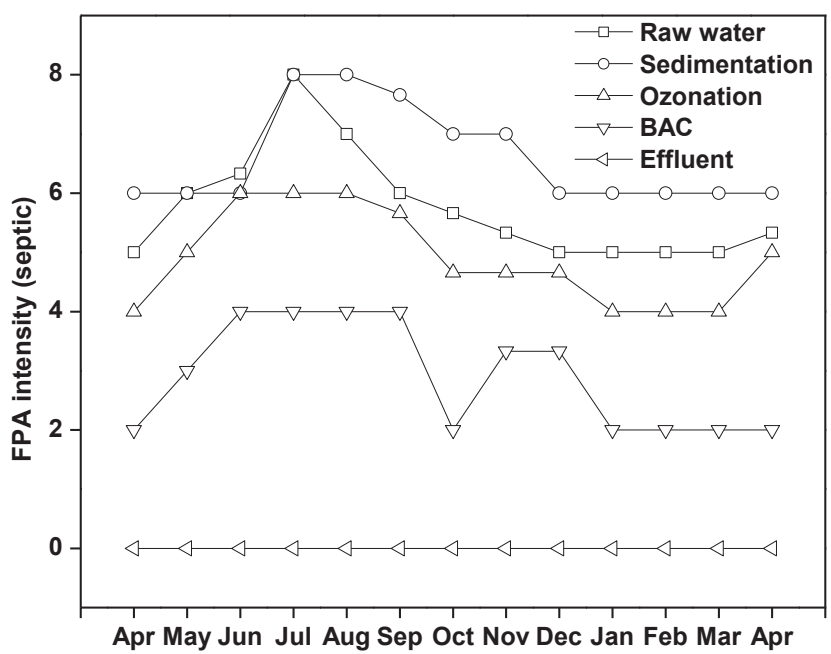

(b)

Fig. 1. Variations of odor intensities in raw water and the effluent of each treatment step. (a): musty odor, (b): septic odor.

with two types of odors, the septic and musty odors, with an FPA intensity of 5-8 and 4-7, respectively, in raw water over the period from April, 2014 to April, 2015. A distinct seasonal change tendency of the odors' intensity was observed, with the maximal values appearing in summer. In our previous investigation conducted in 2009 , the intensity range of musty odor was $1.0-5.3$, and Phormidium spp. (cyanobacteria) had been found to be responsible for 2-MIB production (Sun et al., 2013). However, the musty odor intensity increased significantly in this study, suggesting that the activity of odor producing cyanobacteria might be increased (Liu et al., 2016; Wang et al., 2016).

The variations of the odor intensities of the effluents from sedimentation, ozonation, BAC and the final treated water are shown in Fig. 1 and Table S2. The musty odor could be completely removed through ozonation and BAC treatment, while the septic odor could still be detected in the effluent of BAC. The septic odor disappeared in the final treated water, perhaps through the biological effect of sand filtration and oxidation effect of chlorination (Zoeteman et al., 1980; Cho et al., 1991; Lin et al., 2002; Wenk et al., 2013). In this WTP, pre-chlorination was not adopted. Prechlorination process may remove part of the septic odorants, but increase the earthy-musty odor by promoting algal cell lysis (Ridal et al., 1999; Lin et al., 2009). So the effects of pre-chlorination should be studied in the future. It should be noted that the intensities of both the septic and musty odors increased markedly after sedimentation. The sludge bed in the sedimentation tanks is the sink of algal cells and organic particles (Zamyadi et al., 2012; Ho et al., 2013). Release of intracellular odorants could lead to an increase of the musty odor intensity (Zamyadi et al., 2015). At the same time, the organic particles could become an important source for some reducing odorants like thioethers if sludge is not removed from the sedimentation tank in a timely fashion (Lomans et al., 1997). This process will be further discussed later.

\subsection{Odorant removal in WTP}

A total of eighteen odorants were frequently detected in the HP source water, as shown in Fig. 2 and Table S3. Among the detected odorants, two important musty odorants, 2-MIB and geosmin, were detected with concentrations of 7.11-18.90 ng/L and 6.55-35.76 ng/L, respectively. 2-MIB produced by Phormidium spp. has been found to be the major musty odorant in HP River in our previous studies (Li et al., 2012b; Sun et al., 2013). In this study, however, geosmin became the major musty odorant. It is thus possible that the algal compositions might have changed because 2-MIB and geosmin are usually produced by different algae (Watson, 2010). And, the species responsible for the production of geosmin needs further study. The aldehyde compounds, including hexanal, heptanal, nonanal and decanal, were mainly associated with algal metabolites (Yasuhara and Fuwa, 1982; Watson, 2004; Zhang et al., 2013).

The thioethers, including DEDS and DMDS, have been reported as typical septic odorants in drinking water (Watson, 2004; Yang et al., 2008), which were associated with bio-industry (Hwang et al., 1995; Smet and Van Langenhove, 1998) and swine operation processes (Schiffman et al., 2001). Bis(2-chloroisopropyl) ether, as a septic odorant, has been discovered in drinking water contaminated by industrial outfall (Kleopfer and Fairless, 1972; Steltenpohl and Graczova, 2008). This odorant was also detected in Huangpu River source water in our previous investigation (Yu et al., 2009).

Several nitrogen containing compounds including pyrazine, tetramethyl-pyrazine, pyridine, thiazole and 2-nitro-phenol, which may be associated with the stinky/fishy/sour/medicinal like odors (Watson, 2004), should be related with industrial discharge. For

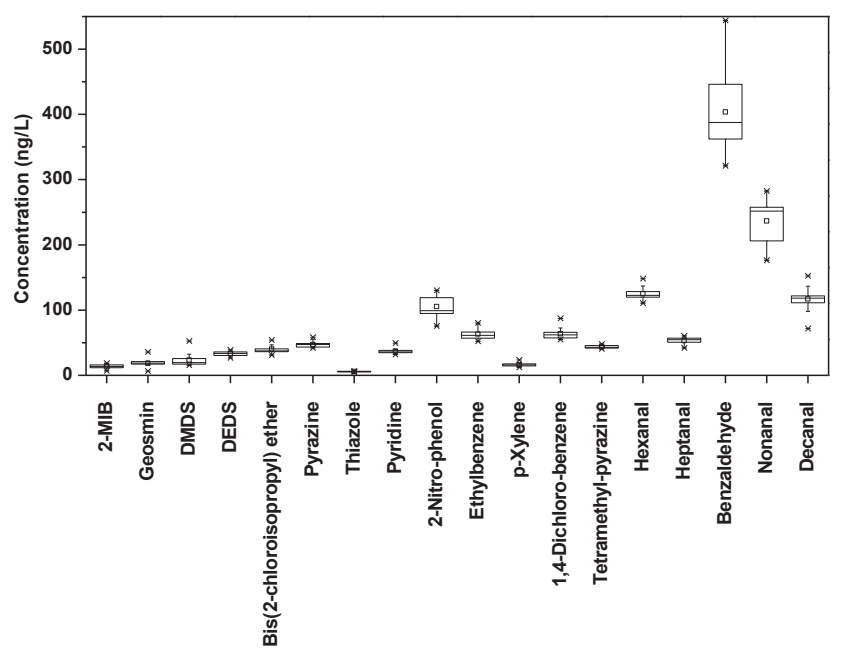

Fig. 2. The concentrations of detected odorants in raw water. 
example, Pandey reported that pyridine was detected in waste gas emissions with unpleasant fishy odor (Pandey et al., 2007). Thiazole was an important flavor compound in food fields with unpleasant smell (Mahattanatawee et al., 2007). 2-nitro-phenol could arise from natural substance degradation, industrial activities and agricultural practices (Davi and Gnudi, 1999). The presence of the above compounds and 1.4-dichloro-benzene, p-xylene and ethylbenzene demonstrated that the HP River is suffering from different types of domestic and industrial pollution. Actually, this river is located in the most populated and industrialized area in China, which makes it easily contaminated (Ren et al., 2003; Yang et al., 2007; Wang et al., 2008).

The average OAVs of the detected 18 odorants are shown in Fig. 3. Geosmin exhibited the highest average OAV of 4.54, followed by bis(2-chloroisopropyl) ether, DEDS, 2-MIB, DMDS, nonanal, benzaldehyde, decanal, pyridine, etc. A compound with an OAV over 1 is considered to be important in constituting the odor profile (Pang et al., 2012). So 2-MIB and geosmin should be the key odorants responsible for the musty odor, while DMDS, DEDS and bis(2chloroisopropyl) should be the key odorants related to the septic odor.

Fig. 4 shows the changes of the total OAVs including the two musty odorants and the three septic ones over the water treatment processes, respectively. The total OAV of the musty odorants was 0.38 after BAC treatment. However, the total OAV of the septic odorants was still 0.79 after BAC treatment, which could explain why the $\mathrm{O}_{3}$-BAC treatment was still not sufficient for the removal of the septic odor. Generally speaking, septic odor and odorants as DMDS, DEDS could be removed efficiently by oxidation processes including ozonation and activated carbon (Vega et al., 2013, 2014, 2015). However, small part of septic odor and odorants were still detected after BAC treatment. So further increase of ozone dose was needed to ensure complete removal of septic odor by $\mathrm{O}_{3}-\mathrm{BAC}$. However, the ozone dose should be carefully controlled to prevent the formation of bromate considering the high concentration of bromide $(215-417 \mu \mathrm{g} / \mathrm{L})$ in raw water of HP River (von Gunten, 2003b; Wang et al., 2014).

The removal of each odorant is summarized as shown in Fig. S2 and Table S4. It is clear that most of the odorants exhibited an increasing trend after sedimentation, suggesting that release of these odorants occurred during the sedimentation process. Organic particles including algal cells are trapped in flocs during coagulation, and then settle down in the bottom of settlers until the discharge of sludge. Algal cells trapped in sludge may rupture when

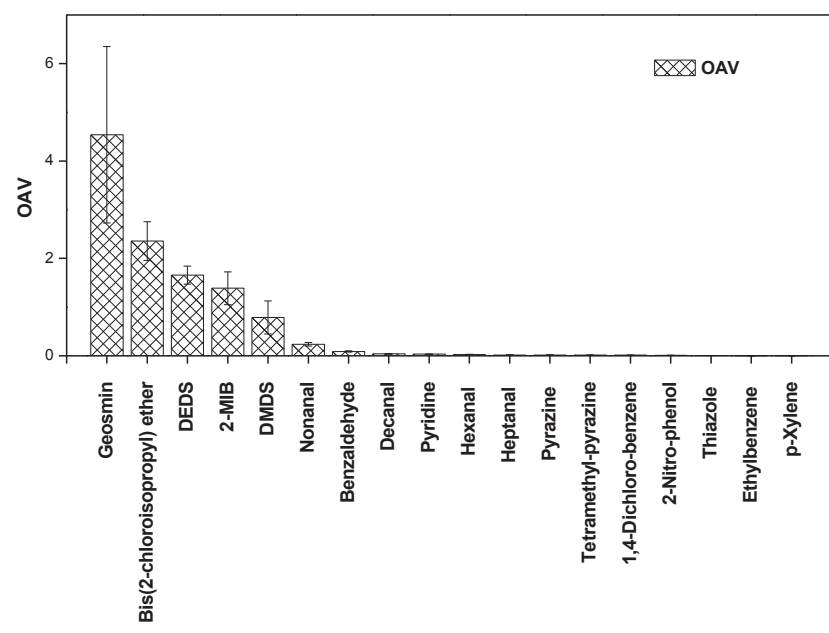

Fig. 3. OAV ranking of the detected odorants in raw water.

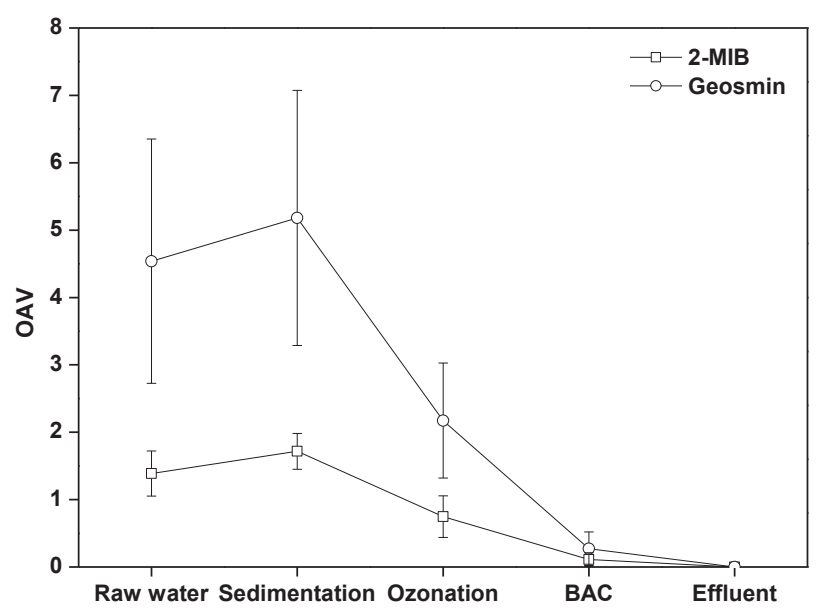

(a)

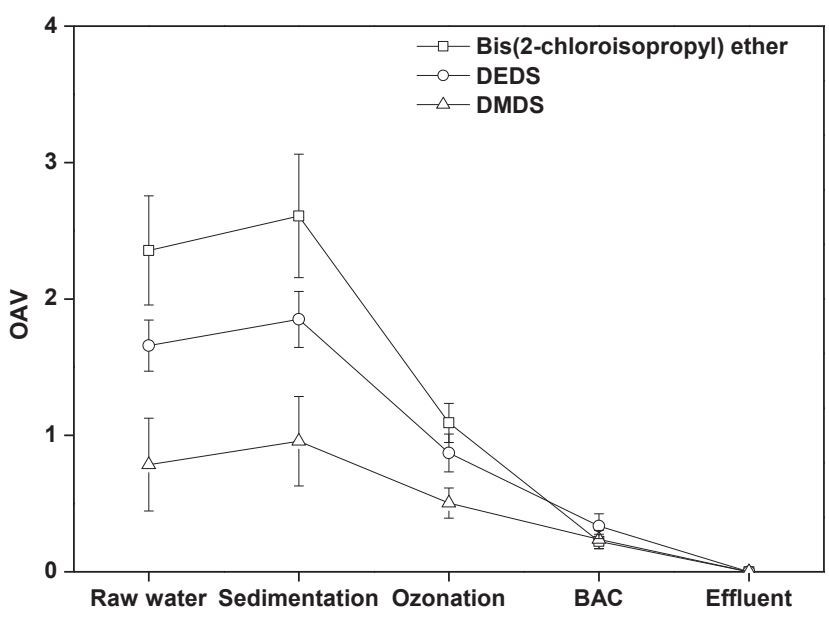

(b)

Fig. 4. Changes of the total OAVs of the musty and septic odorants over the water treatment process. (a): Sum of musty odorants (2-MIB, geosmin), (b): Sum of septic odorants (bis(2-chloroisopropyl) ether, DEDS, DMDS).

the sludge residence time in the sedimentation tank was long enough (sludge was removed once a day from the sedimentation tank) or the sedimentation sludge removal was incomplete, releasing the intracellular odorants (Schmidt et al., 2002, 2009; Kommineni et al., 2009; Ho et al., 2012; Li et al., 2012a, 2012b; Zamyadi et al., 2012, 2013, 2014; Ho et al., 2013). On the other hand, anaerobic digestion could easily take place in sedimentation sludge because of the presence of algal cells and other organic materials. Some septic odorants such as thioethers (DMDS, DEDS, etc.) could be generated (Lomans et al., 1997), and part of the odorants adsorbed on the particles could be dissolved into water during the anaerobic digestion. Thus this study demonstrated that the release of odorants could take place under normal operational conditions. Anaerobic digestion and rupturing of algal cells could be alleviated by reducing the residence time of sedimentation sludge. Thus increasing sludge discharge frequency should be an effective approach to prevent the release of odorants. However, the increase of sludge discharge frequency means the increase of wastewater volume during water production, and the total suspended solid in the effluent of the settler may be affected. Further study is needed to allow a better management of sedimentation sludge.

It is clear that ozonation was very effective in the removal of most odorants other than aldehydes. The aldehydes' concentrations 
increased after ozonation, but then decreased significantly after BAC treatment because the aldehydes are biodegradable. It is interesting that almost all of the detected odorants were significantly reduced after $\mathrm{BAC}$ treatment. The $\mathrm{O}_{3}-\mathrm{BAC}$ process was put into use starting December 2012, so the activated carbon had been used for seventeen months before this study. It is thus speculated that the removal of the odorants was mainly accomplished through biodegradation. Biodegradation of some odorants including geosmin, 2-MIB, DEDS, DMDS, pyrazine, etc., has also been reported in previous studies (Rappert and Muller, 2005; Persson et al., 2007; Arellano-Garcia et al., 2012). This study clearly demonstrated that ozonation and biological degradation are two important approaches for the mitigation of complicated odor problems contributed by musty and septic odorants.

\section{Conclusions}

In this study, the removal performance for odors and odorants in a water treatment plant adopting $\mathrm{O}_{3}$-BAC process were evaluated over a period for 13 months. The $\mathrm{O}_{3}$-BAC process was effective in the simultaneous removal of the musty odor, mainly contributed by geosmin and 2-MIB, and the septic odor, mainly contributed by bis(2-chloroisopropyl) ether, DEDS and DMDS. Because of the much higher concentrations of septic odorants, however, complete removal of the septic odor needs further treatment by sand filtration and chlorination. It should be noted that the sedimentation process needs careful management, because release of odorants occurred during this treatment.

\section{Acknowledgements}

This study was supported by Funds for the National Natural Science Foundation of China (No. 21377144), the Major Science and Technology Program for Water Pollution Control and Treatment (No. 2015ZX07406001X07403-002), and the "135" Major Project of Research Center for Eco-Environment Science (YSW2013A02).

\section{Appendix A. Supplementary data}

Supplementary data related to this article can be found at http:// dx.doi.org/10.1016/j.watres.2016.05.017.

\section{References}

APHA, 2005. Standard Methods for the Examination of Water and Wastewater American Public Health Association.

Antonopoulou, M., Evgenidou, E., Lambropoulou, D., Konstantinou, I., 2014. A review on advanced oxidation processes for the removal of taste and odor compounds from aqueous media. Water Res. 53, 215-234.

Andreadakis, A.D., Mamais, D., Gavalakis, E.A., Noutsopoulos, C., Kouris, N., Nikitopoulos, G., 2010. Removal of taste and odour from potable water by ozone and Powdered Activated Carbon (PAC). Int. J. Environ. Waste Manag. 5 (3-4), 392-409.

Atasi, K.Z., Chen, T., Huddieston, J.I., Young, C.C., Suffet, I.H., 1999. Factor screening for ozonating the taste- and odor-causing compounds in source water at Detroit, USA. Water Sci. Technol. 40 (6), 115-122.

Arellano-Garcia, L., Gonzalez-Sanchez, A., Van Langenhove, H., Kumar, A., Revah, S. 2012. Removal of odorant dimethyl disulfide under alkaline and neutral conditions in biotrickling filters. Water Sci. Technol. 66 (8), 1641-1646.

Burdack-Freitag, A., Schieberle, P., 2012. Characterization of the key odorants in raw Italian hazelnuts (Corylus avellana L. var. Tonda Romana) and roasted hazelnut paste by means of molecular sensory science. J. Agric. Food Chem. 60 (20), 5057-5064.

Cho, K.S., Hirai, M., Shoda, M., 1991. Degradation characteristics of hydrogen sulfide, methanethiol, dimethyl sulfide and dimethyl disulfide by Thiobacillus thioparus DW44 isolated from peat biofilter. J. Ferment. Bioeng. 71 (6), 384-389.

Cook, D., Newcombe, G., Sztajnbok, P., 2001. The application of powdered activated carbon for MIB and geosmin removal: predicting PAC doses in four raw waters. Water Res. 35 (5), 1325-1333.

Davi, M.L., Gnudi, F., 1999. Phenolic compounds in surface water. Water Res. 33 (14), 3213-3219.
Geering, F., 1999. Ozone applications the state-of-the-art in Switzerland. Ozone Sci. Eng. 21 (2), 187-200.

Guo, Q.Y., Li, X., Yu, J.W., Zhang, H.F., Zhang, Y., Yang, M., Lu, N., Zhang, D., 2015. Comprehensive two-dimensional gas chromatography with time-of-flight mass spectrometry for the screening of potent swampy/septic odor-causing compounds in two drinking water sources in China. Anal. Methods 7 (6), 2458-2468

Guo, Q.Y., Yu, J.W., Yang, K., Wen, X.D., Zhang, H.F., Yu, Z.Y., Li, H.Y., Zhang, D., Yang, M., 2016. Identification of complex septic odorants in Huangpu River source water by combining the data from gas chromatography-olfactometry and comprehensive two-dimensional gas chromatography using retention indices. Sci. Total Environ. 556, 36-44.

Ho, L., Newcombe, G., Croué, J.P., 2002. Influence of the character of NOM on the ozonation of MIB and geosmin. Water Res. 36 (3), 511-518.

Ho, L., Dreyfus, J., Boyer, J., Lowe, T., Bustamante, H., Duker, P., Meli, T., Newcombe, G., 2012. Fate of cyanobacteria and their metabolites during water treatment sludge management processes. Sci. Total Environ. 424, 232-238.

Ho, L., Barbero, A., Dreyfus, J., Dixon, D.R., Qian, F., Scales, P.J., Newcombe, G., 2013. Behaviour of cyanobacterial bloom material following coagulation and/or sedimentation. J. Water Supply. Res. Technol. 62, 350-358.

Hwang, Y., Matsuo, T., Hanaki, K., Suzuki, N., 1995. Identification and quantification of sulfur and nitrogen-containing odorous compounds in waste water. Water Res. 29 (2), 711-718.

Jo, C.H., Dietrich, A.M., Tanko, J.M., 2011. Simultaneous degradation of disinfection byproducts and earthy-musty odorants by the UV/H2O2 advanced oxidation process. Water Res. 45 (8), 2507-2516.

Jung, S., Baek, K., Yu, M., 2004. Treatment of taste and odormaterials by oxidation adsorption. Water Sci. Technol. 49 (9), 289-295.

Khiari, D., Suffet, I., Barrett, S.E., 1995. The determination of compounds causing fishy/swampy odors in drinking water supplies. Water Sci. Technol. 31 (11), 105-112.

Kleopfer, R.D., Fairless, B.J., 1972. Characterization of organic components in a municipal water supply. Environ. Sci. Technol. 6 (12), 1036-1037.

Kommineni, S., Amante, K., Karnik, B., Sommerfeld, M., Dempster, T., 2009. Strategies for Controlling and Mitigating Algal Growth within Water Treatment Plants. Water Research Foundation, Denver, Colorado, USA.

Li, L., Gao, N.Y., Deng, Y., Yao, J.J., Zhang, K.J., 2012a. Characterization of intracellular \& extracellular algae organic matters (AOM) of Microcystic aeruginosa and formation of AOM-associated disinfection byproducts and odor \& taste compounds. Water Res. 46 (4), 1233-1240.

Li, Z.L., Hobson, P., An, W., Burch, M.D., House, J., Yang, M., 2012b. Earthy odor compounds production and loss in three cyanobacterial cultures. Water Res. 46 (16), 5165-5173

Liang, C., Wang, D., Chen, J., Zhu, L., Yang, M., 2007. Kinetics analysis on the ozonation of MIB and geosmin. Ozone Sci. Eng. 29, 185-189.

Lin, T.-F., Wong, J.-Y., Kao, H.-P., 2002. Correlation of musty odor and 2-MIB in two drinking water treatment plants in South Taiwan. Sci. Total. Environ. 289 (1-3) 225-235.

Lin, T.-F., Chang, D.-W., Lien, S.-K., Tseng, Y.-S., Chiu, Y.-T., Wang, Y.-S., 2009. Effect of chlorination on the cell integrity of two noxious cyanobacteria and their releases of odorants. J. Water Supply. Res. Technol. 58 (8), 539-551.

Liu, H., Pan, D., Zhu, M., Zhang, D., 2016. Occurrence and emergency response of 2Methylisoborneol and geosmin in a large shallow drinking water reservoir. CLEAN - Soil, Air, Water 44 (1), 63-71.

Lomans, B.P., Smolders, A.J.P. Intven, L.M., Pol, A., denCamp, H., vanderDrift, C., 1997. Formation of dimethyl sulfide and methanethiol in anoxic freshwater sediments. Appl. Environ. Microb. 63 (12), 4741-4747.

Mahattanatawee, K., Perez-Cacho, P.R., Davenport, T., Rouseff, R., 2007. Comparison of three lychee cultivar odor profiles using gas chromatography-olfactometry and gas chromatography-sulfur detection. J. Agric. Food Chem. 55 (5), 1939-1944.

Mizuno, T., Ohara, S., Nishimura, F., Tsuno, $\mathrm{H}$., 2011. $\mathrm{O}_{3} / \mathrm{H}_{2} \mathrm{O}_{2}$ process for both removal of odorous algal-derived compounds and control of bromate ion formation. Ozone Sci. Eng. 33 (2), 121-135.

Newcombe, G., Cook, D., 2002. Influences on the removal of tastes and odours by PAC. J. Water Supply. Res. Technol. 51 (8), 463-474.

Newcombe, G., Drikas, M., Hayes, R., 1997. Influence of characterised natural organic material on activated carbon adsorption: II. Effect on pore volume distribution and adsorption of 2-methylisoborneol. Water Res. 31 (5), 1065-1073.

Pandey, R.A., Padoley, K.V., Mukherji, S.S., Mudliar, S.N., Vaidya, A.N., Rajvaidya, A.S., Subbarao, T.V., 2007. Biotreatment of waste gas containing pyridine in a biofilter. Bioresour. Technol. 98 (12), 2258-2267.

Pang, X.L., Guo, X.F., Qin, Z.H., Yao, Y.B., Hu, X.S., Wu, J.H., 2012. Identification of aroma-active compounds in Jiashi muskmelon juice by GC-O-MS and OAV calculation. J. Agric. Food Chem. 60 (17), 4179-4185.

Persson, F., Heinicke, G., Hedberg, T., Hermansson, M., Uhl, W., 2007. Removal of geosmin and MIB by biofiltration - an investigation discriminating between adsorption and biodegradation. Environ. Technol. 28 (1), 95-104.

Rappert, S., Muller, R., 2005. Microbial degradation of selected odorous substances. Waste Manag. 25 (9), 940-954.

Ren, W., Zhong, Y., Meligrana, J., Anderson, B., Watt, W.E., Chen, J., Leung, H.-L., 2003. Urbanization, land use, and water quality in Shanghai: 1947-1996. Environ. Int. 29 (5), 649-659.

Ridal, J.J., Brownlee, B., Lean, D.R.S., 1999. Occurrence of the odor compounds, 2Methylisoborneol and geosmin in Eastern lake Ontario and the Upper St. 
Lawrence river. J. Great Lakes. Res. 25 (1), 198-204.

Schmidt, W., Willmitzer, H., Bornmann, K., Pietsch, J., 2002. Production of drinking water from raw water containing cyanobacteria. Pilot plant studies for assessing the risk of microcystin breakthrough. Environ. Toxicol. 17 (4), 375-385.

Schmidt, W., Petzoldt, H., Bornmann, K., Imhof, L., Moldaenke, C., 2009. Use of cyanopigment determination as an indicator of cyanotoxins in drinking water. Water Sci. Technol. 59 (8), 1531-1540.

Schiffman, S.S., Bennett, J.L., Raymer, J.H., 2001. Quantification of odors and odorants from swine operations in North Carolina. Agric. For. Meteorol. 108 (3), $213-240$.

Smet, E., Van Langenhove, H., 1998. Abatement of volatile organic sulfur compounds in odorous emissions from the bio-industry. Biodegradation 9 (3-4), 273-284.

Srinivasan, R., Sorial, G.A., 2011. Treatment of taste and odor causing compounds 2methyl isoborneol and geosmin in drinking water: a critical review. J. Environ. Sci. 23 (1), 1-13.

Steltenpohl, P., Graczova, E., 2008. Vapor-liquid equilibria of selected components in propylene oxide production. J. Chem. Eng. Data 53 (7), 1579-1582.

Suffet, I.H., Khiari, D., Bruchet, A., 1999. The drinking water taste and odor wheel for the millennium: beyond geosmin and 2-methylisoborneol. Water Sci. Technol. 40 (6), 1-13.

Sun, D.L., Yu, J.W., An, W., Yang, M., Chen, G.G., Zhang, S.J., 2013. Identification of causative compounds and microorganisms for musty odor occurrence in the Huangpu River, China. J. Environ. Sci. 25 (3), 460-465.

Sun, D.L., Yu, J.W., Yang, M., An, W., Zhao, Y.Y., Lu, N., Yuan, S.G., Zhang, D.Q., 2014. Occurrence of odor problems in drinking water of major cities across China. Front. Environ. Sci. Eng. 8 (3), 411-416.

Vega, E., Lemus, J., Anfruns, A., Gonzalez-Olmos, R., Palomar, J., Martin, M.J., 2013. Adsorption of volatile sulphur compounds onto modified activated carbons: effect of oxygen functional groups. J. Hazard. Mater. 258, 77-83.

Vega, E., Martin, M.J., Gonzalez-Olmos, R., 2014. Integration of advanced oxidation processes at mild conditions in wet scrubbers for odourous sulphur compounds treatment. Chemosphere 109, 113-119.

Vega, E., Sánchez-Polo, M., Gonzalez-Olmos, R., Martin, M.J., 2015. Adsorption of odorous sulfur compounds onto activated carbons modified by gamma irradiation. J. Colloid Interface Sci. 457, 78-85.

von Gunten, U., 2003a. Ozonation of drinking water: Part I. Oxidation kinetics and product formation. Water Res. 37 (7), 1443-1467.

von Gunten, U., 2003b. Ozonation of drinking water: Part II. Disinfection and byproduct formation in presence of bromide, iodide or chlorine. Water Res. 37 (7), 1469-1487.

Wang, J., Da, L., Song, K., Li, B.-L., 2008. Temporal variations of surface water quality in urban, suburban and rural areas during rapid urbanization in Shanghai, China. Environ. Pollut. 152 (2), 387-393.
Wang, H., Dai, M., Liu, J., Kao, S.J., Zhang, C., Cai, W.J., Wang, G., Qian, W., Zhao, M. Sun, Z., 2016. Eutrophication-driven hypoxia in the East China sea off the Changjiang Estuary. Environ. Sci. Technol. 50 (5), 2255-2263.

Wang, Y.J., Yu, J.W., Zhang, D., Yang, M., 2014. Addition of hydrogen peroxide for the simultaneous control of bromate and odor during advanced drinking water treatment using ozone. J. Environ. Sci. 26 (3), 550-554.

Watson, S.B., 2004. Aquatic taste and odor: a primary signal of drinking - water integrity. J. Toxicol. Env. Heal. A 67 (20-22), 1779-1795.

Watson, S.B., 2010. Algae: Source to Treatment-chapter 15 Algal Taste and Odor. AWWA, pp. 329-369.

Wenk, J., Aeschbacher, M., Salhi, E., Canonica, S., von Gunten, U., Sander, M., 2013. Chemical oxidation of dissolved organic matter by chlorine dioxide, chlorine, and ozone: effects on its optical and antioxidant properties. Environ. Sci. Technol. 47 (19), 11147-11156.

Yang, H.J., Shen, Z.M., Zhang, J.P., Wang, W.H., 2007. Water quality characteristics along the course of the Huangpu River (China). J. Environ. Sci. 19 (10), 1193-1198.

Yang, M., Yu, J.W., Li, Z.L., Guo, Z.H., Burch, M., Lin, T.-F., 2008. Taihu Lake not to blame for Wuxi's woes. Science 319 (5860), 158-158.

Yasuhara, A., Fuwa, K., 1982. Characterization of odorous compounds in rotten bluegreen algae. Agr. Biol. Chem. 46 (7), 1761-1766.

Yu, J.W., Zhao, Y.M., Yang, M., Lin, T.-F., Guo, Z.H., Gu, J.N., Li, S., Han, W., 2009. Occurrence of odour-causing compounds in different source waters of China. J. Water Supply. Res. Technol. 58 (8), 587-594.

Zamyadi, A., Henderson, R., Stuetz, R., Hofmann, R., Ho, L., Newcombe, G., 2015. Fate of geosmin and 2-methylisoborneol in full-scale water treatment plants. Water Res. 83, 171-183.

Zamyadi, A., MacLeod, S.L., Fan, Y., McQuaid, N., Dorner, S., Sauvé, S., Prévost, M. 2012. Toxic cyanobacterial breakthrough and accumulation in a drinking water plant: a monitoring and treatment challenge. Water Res. 46 (5), 1511-1523.

Zamyadi, A., Dorner, S., Sauvé, S., Ellis, D., Bolduc, A., Bastien, C., Prévost, M., 2013. Species-dependence of cyanobacteria removal efficiency by different drinking water treatment processes. Water Res. 47 (8), 2689-2700.

Zamyadi, A., Dorner, S., Ndong M., Ellis, D., Bolduc, A., Bastien, C. Prevost, M., 2014 Application of in vivo measurements for the management of cyanobacteria breakthrough into drinking water treatment plants. Environ. Sci. Proc. Impacts 16 (2), 313-323.

Zhang, K.J., Lin, T.F., Zhang, T.Q., Li, C., Gao, N.Y., 2013. Characterization of typical taste and odor compounds formed by Microcystis aeruginosa. J. Environ. Sci. 25 (8), 1539-1548.

Zoeteman, B.C.J., Harmsen, K., Linders, J.B.H.J., Morra, C.F.H., Slooff, W., 1980 Persistent organic pollutants in river water and ground water of the Netherlands. Chemosphere 9 (4), 231-249. 